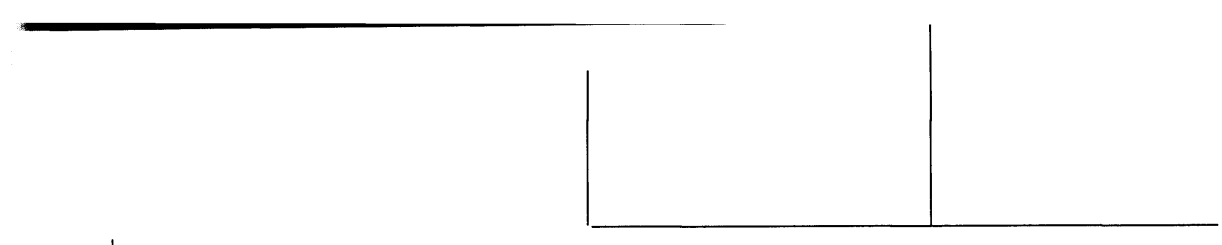

Rev. Latinoam. Psicopat. Fund., X, 3, 526-535

\title{
Primitivo e loucura (Final do prefácio e capítulo 1) ${ }^{1}$
}

Arthur Ramos ${ }^{2}$

\section{(Final do Prefácio)}

\section{Conclusões Gerais}

Pela simples leitura desta síntese, vê-se que influências várias e aparentemente heteróclitas atuaram no meu espírito até a visão unificada de um plano definitivo. Não surgiu, pois, de improviso o meu trabalho. Meditei-o longamente, e de muito tempo a idéia mestra me aparecera tênue, vaga, imprecisa como uma nebulosa. Teve a sua lenta incubação, ao tempo em que eu consultava notas, elaborava planos, procurando inteirar-me de uma exegese bibliográfica que sabia imensa nesse domínio, mas que infelizmente achava tão escassa em nossas bibliotecas.

Não é novo o título. Eu o tomei emprestado de uma monografia de Tanzi "Il folk-lore nella patologia mentale" de uma

1. Agradecemos ao Prof. Dr. Cláudio Luiz Pereira pela inestimável colaboração no estabelecimento do texto. A ortografia foi atualizada, além de pequenas alterações de palavras, visando a melhor compreensão do leitor. As notas foram mantidas conforme versão original.

2. Ramos, Arthur. Primitivo e loucura. 1926. Tese (doutoramento em Medicina), Faculdade de Medicina da Bahia, Salvador. 


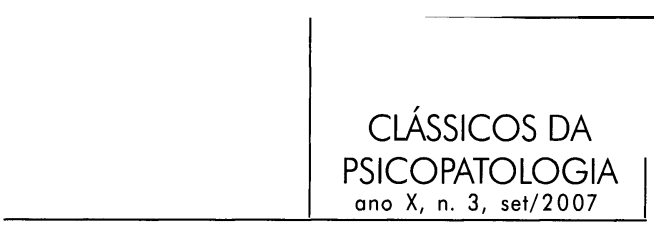

influência preponderante em minha obra, se bem que nem sempre coincidam as nossas conclusões. Mais recentemente, Paulo Schilder dá um titulo mais ou menos equivalente: "Völkerpsychologie und Psychiatrie" a um dos capítulos do seu livro Wahn und Erkenntnis, que cito muitas vezes em meu trabalho.

Procurei aproximar estudos e pesquisas que, partindo de pontos de vista diferentes e independentes uns dos outros, chegaram contudo às mesmas conclusões.

O meu trabalho é, assim, uma tentativa de síntese e de aproximação de todos esses materiais dispersos, recolhidos por escolas diversas e por especialistas em disciplinas aparentemente opostas. É uma modesta contribuição a esse movimento recente que se processa nos domínios da psicologia normal e patológica, que procura estudar o homem como um animal gregário, perscrutando as suas reações sociais, o seu "comportamento", como faz a escola americana do behavior.

É uma tentativa de aplicação do método comparativo - etnológico e folclórico - aos fatos da psiquiatria. Por isso, os problemas de que trato não surgiram das retortas e reativos dos laboratórios de clínica. Eles são de outra natureza e necessitam de outra espécie de observação bem mais vasta e bem mais complexa: a observação das relações inter-humanas na ambiência social e dos distúrbios da função gregária no alienado.

E isso, hão de concordar comigo, não é problema que se resolva entre as quatro paredes de um laboratório.

Dirijo aqui a expressão dos meus efusivos agradecimentos ao professor Mário Leal, catedrático de Clínica Psiquiátrica da nossa faculdade, que pôs gentilmente à minha disposição a biblioteca e material do seu serviço clínico do Hospital de S. João de Deus; e ao jovem professor Estácio de Lima, catedrático de Medicina Legal, por algumas preciosas indicações bibliográficas que foram de imensa utilidade na feitura de meu trabalho.

Bahia, novembro de 1926

Arthur Ramos

\section{Capítulo I}

Aqueles especialistas que, como os etnólogos, estudam os selvagens e seus atos mentais e modos de vida, ou, como os demopsicólogos, seguiram a evolução e persistência de hábitos primitivos nas sociedades mais avançadas em civilização, recolhendo amplo material do folclore, estavam longe de imaginar que a seus 


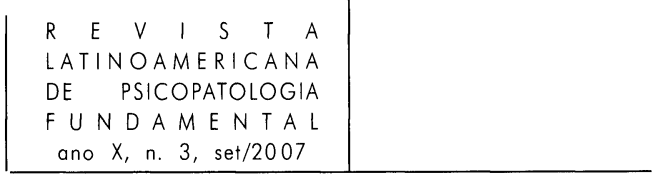

campos de pesquisa lançasse a psiquiatria as suas vistas ambiciosas, na ânsia sempre crescente de surpreender os segredos da psique humana desviada da normalidade.

Já em psicologia, Ardigo acenará para a importância exegética desses documentos etnológicos como método de investigação extropectiva. ${ }^{3}$ Luquet $^{4}$ e LévyBrühl, ${ }^{5}$ da mesma sorte exprobrando, com Ribot, o erro clássico de se tomar como modelo psicológico humano o indivíduo "branco, adulto e civilizado", procuraram reabilitar o método comparativo que Augusto Comte enunciara numa fórmula célebre, mas infelizmente pouco lembrada, para a mais exata definição do retrato psicológico do "homem", explicado pela "humanidade" e não esta por aquele, como houvera feito, até então, o nosso antropomorfismo de civilizados.

$\mathrm{O}$ interesse da psicopatologia pelo material etnológico não foi menor, quando procurou estabelecer cotejos e analogias entre as funções mentais do primitivo ${ }^{6}$ e os quadros clínicos que ela registra diariamente dentro dos manicômios.

Entre primitivo e louco descobriram-se aqueles mesmos pontos de contato em suas fórmulas respectivas de exteriorização mental que muitos autores já haviam assinalado em condições outras como o sonho e a atividade artística. É por isso que ao estudo das relações entre o louco e o primitivo se prendem intimamente estas outras questões de analogias entre sonho, arte e loucura de um lado, e sonho, arte, neurose e atividade primitiva do outro. ${ }^{7}$

3. Artigo "Psicologia", 3. ed., Parte IV, p. 174-178. Cf. Ingenieiros. Princípios de psicologia. Buenos Aires, 1915. p. 297 e segs.

4. Luquet. Utilisations psychologiques des documents etnographiques. Revue Philosophique. Tome LXX, p. 160, 1915.

5. Lévy-Brühl. Les fonctions mentales dans sociétés inférieures. Paris: Alcan, 1922. p. 2 e segs.

6. Em psicologia, seria preferível o termo "primitivo" ao de "selvagem", de uma significação mais sociológica. "Par ce terme [primitivo], diz Levy-Brühl, impropre, mais d'um usage presque indispensable, nous entendons simplement désigner les membres des sociétés les plus simples que nous connaissions" (p. 2). Acho que a psicologia poderia englobar na expressão de "primitivo" o conceito da mentalidade atrasada tanto na escala filogenética (raças selvagens que já desapareceram e só conhecidas por documentos históricos, ou as que existem ainda hoje em vários pontos do globo), como na escala ontogenética. E é justamente a psicologia moderna, com o advento da psicanálise, que frisa os pontos de contato entre o selvagem e a criança. Vejase nesse sentido, a esplêndida obra de um pedagogo, de influência freudística pronunciada: Jean Piaget, Le langage et la pensée chez l'enfant. Genève, 1923. p. 59 e segs.

7. Storch, escrevendo o seu trabalho sobre a analogia entre o esquizofrênico e o primitivo, afirma que esse problema "se junta acidentalmente à questão da aproximação entre o sonho e psicologia do primitivo, sonho e desordem do espírito": Das Problem der vorliegenden Arbeit, die Frage nach Beziehungen schizophrenen und archaischprimitiven Erlebens ist historisch aus 


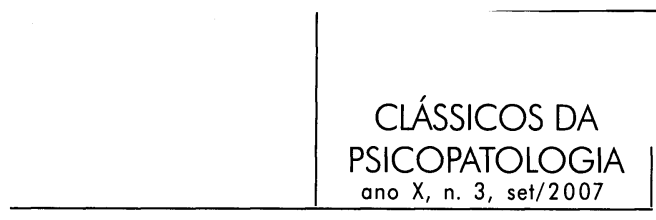

Desde a Antigüidade se tinham comparado os processos simbólicos do sonho com a loucura, fato posto em evidência depois dos belos estudos de Ball, Baillarger, de Sant, Maury, Mourly-Vold, Moreau (de Tours) etc., em suas "Relações do físico e do moral", que nos deram belas páginas onde se referem à analogia de estrutura entre o sonho e a mentalidade mórbida. ${ }^{8}$ Moreau (de Tours $)^{9}$ teceu considerações idênticas nos seus experimentos em indivíduos sob a influência do haxixe. Maury ${ }^{10}$ frisa a incoerência dos sonhos comparando a atividade onírica aos processos da psicose.

Ball e Baillarger ${ }^{11}$ reconheceram na atividade onírica identidade de processo com o mecanismo das alucinações. Morseli foi mais além quando afirmou que a afinidade entre sonho e loucura é "algo mais do que verbal: a analogia é real, principalmente no que respeita a maneira de se portar a memória no sonho e na loucura". ${ }^{12}$

Nietzsche, como faz lembrar Storch, nos deixou vistas intuitivas sobre as relações existentes não já entre o sonho e a loucura, mas entre o sonho e o pensamento primitivo. Ele achou que o sonho desperta em nós antigas situações trazendo outra vez à tona do psiquismo consciente a velha e primitiva cultura humana que jazia esquecida para trás dos tempos. (Der Traum bringt uns in ferne Zustände der menschlichen Kultur wieder zurück... $)^{13}$

As relações entre arte e pensamento primitivo, arte e alienação mental, que hoje constituem um dos pontos prediletos de estudo da psicanálise, já tinham sido, muito antes, ou independente de Freud e sua escola, ou observadas de um lado

der allgemeineren Erkenntnis der Zusammenhänge zwischen Traum und primitivem Seelenleben einerseits, Traum und seelischer Störung andererseits herausgewachsen (Alfred Storch. Das archaisch-primitive Erleben und Denken der Schizophrenen. Berlin, 1922, p. 1).

8. Cf. Vaschide. Le sommeil et les rêves. Paris: Flammarion, 1920. p. 116.

9. Moreau (de Tours). Du haschisch et de l'alienation mentale. Études psychologiques. Paris, I v. p. 431, 1845, citado por Vaschide et Vurpas, Psychologie du délire dans les troubles psychopathiques (Encyclopédie scientifique des aide-mémoires), p. 55.

Moreau (de Tours). De l'identité de l'état de rêve et la folie. Annales médico-psychologiques, 1855, p. 373, citado por Ball, Leçons sur les maladies mentales. Paris, 1880-1883, p. 101.

10. Maury. Le sommeil et les rêves, citado por Vaschide, op. cit., p. 114 e segs. Todo este capítulo do livro de Vaschide é dedicado à análise e crítica das pesquisas de Alfredo Maury.

11. Ball. Op. cit., p. 101. Os trabalhos de Baillarger giram mais especialmente em torno "da influência do estado intermediário à vigília e ao sonho sobre a produção e a marcha das alucinações". (Recherches sur les maladies mentales, I. Paris: Masson, 1890. p. 169).

12. Ingenieros. La psicopatología en el arte. Buenos Aires, 1920. p. 72.

13. Nietzsche. Menschliches-Allzumenschliches, I. Hauptstuck, 13, citado por A. Storeli, op. cit. p. 1. 


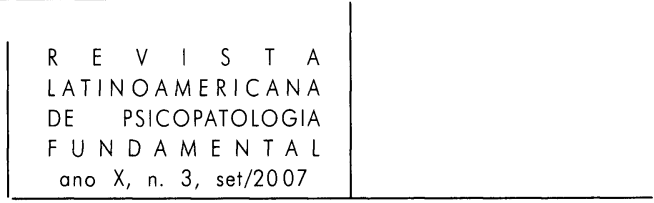

pelos etnólogos, ${ }^{14}$ do outro por psicólogos e alienistas, como Lombroso, Simon, Morel, Antheamne e Dromard, Vinchon etc. ${ }^{15}$

A questão principal do parentesco entre a loucura e o pensamento primitivo foi ventilada, muito antes dos psicólogos e psiquiatras, embora superficial e perfunctoriamente, pelos etnólogos que primeiro reuniram numa vista sintética os materiais esparsos sobre a vida do selvagem. Adolio Bastian, o famoso autor do Mensch in der Geschichte, aflorou, muito de leve, o problema. À sua visão percuciente em tantas coisas de sociopsicologia, não passaria despercebida a analogia entre o selvagem e o louco. ${ }^{16}$ Tylor foi mais longe. Comparou a imaginação exaltada do selvagem com os processos mórbidos da alucinação.

Daríamos melhor conta da intensidade da imaginação mística - diz o célebre etnólogo - comparando-a à alucinação trazida pela moléstia. Com efeito, observase um curioso fenômeno entre os selvagens e mesmo entre as raças de um grau intelectual mais elevado: é o êxtase mórbido provocado pela meditação, o jejum, o narcotismo, a excitação ou a febre, e que apresenta um estado muito comum e tido em consideração nas classes particularmente dispostas ao idealismo místico, estado sob cuja influência diminuem as barreiras que separam a sensação da imaginação. ${ }^{17}$

É assim que o exame dos documentos etnológicos permitiu a Tylor "verificar nos povos antigos e selvagens um estado de imaginação intermediário entre a condição de um cidadão moderno sãmente prosaico e a de um fanático exaltado, de um homem preso de um acesso de febre ardente". ${ }^{18}$ Max Muller, e quem o lembra é Andrew Lang, classificava o estado mental do primitivo como uma "loucura temporária". "Se alguns restos, conclui Lang, dos produtos de uma semelhante imaginação sobrevivem na mitologia dos povos civilizados, devem

14. "L'imagination du poète de nos jours a plus d'un point commun avec l'esprit des tribus incultes à la phase mythologique. Les conceptions imaginatives de l'homme primitif peuvent être étroites, grossières, répulsives, tandis que les fictions plus raffinnées du poète merveilleusement travaillées, peuvent affecter des formes d'une beauté artistique, ravissante, mais il n'en demeure pas moins entre eux, quant à la réalité des idées, un trait d'union que, heureusement ou malheureusement, l'éducation moderne a mis tant de zèle à détruire... " $(\mathrm{E}$. Tylor. La civilization primitive. 1. Trad. franc. Paris, 1876. p. 361).

15. Lombroso. L'homme de génie. 3. ed. Turin-Paris, 1903; Antheaume et Drenard. Poésie et folie. Paris: Doin, 1908; Vinchon. L'art et la folie. Stock, 1924 etc. Para a crítica dessa debatida questão do artista e do gênio-nevrose, vide Hesnard, Les psychoses et les frontières de la folie. Paris: Flammarion, 1924. p.189 e segs.

16. Cf. Tanzi. II folk-lore nella Patologia mentale. Milano, 1890. p. 10.

17. E. Tylor. Op. cit., p. 350.

18. Ibid., p. 360. 


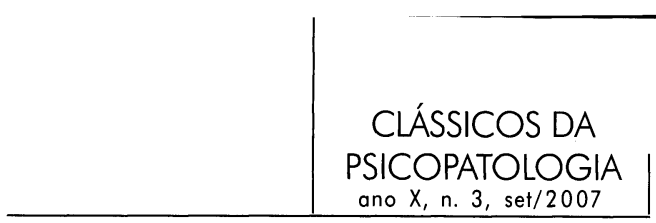

semelhar de muito perto aos produtos de uma 'loucura temporária', outrora universal". ${ }^{19}$

Foi Eugenio Tanzi o primeiro alienista que, partindo do estudo dos subsídios demopsicológicos, admitiu a analogia entre o homem primitivo e o alienado, principalmente o paranóico. Tanzi partiu de uma idéia já ventilada pelo professor Vincenzo Grossi que primeiro chamou a atenção dos psiquiatras para o estudo do folclore, quando esse autor opinou que nele se deveriam encontrar "os resíduos das inteligências primitivas e os elementos das inteligências doentes ou monstruosas". ${ }^{20}$

A escola de Lombroso, que com certeza inspirou os trabalhos de Tanzi sobre o atavismo da paranóia, mostrara analogias entre o delinqüente, o idiota, o epiléptico, de um lado, e o homem primitivo do outro. ${ }^{21}$ Essas analogias foram explicadas pelos conceitos da degeneração e do atavismo que deram lugar a discussões e debates célebres. ${ }^{22}$

Um erudito autor, que se oculta sob as iniciais A. M., fazendo uma revisão crítica do exaustivo estudo do professor Revon, sobre o xintoísmo, do Japão, publicado na Revue de l'Histoire des Réligions, mostrou os pontos de semelhança que há entre certas concepções das religiões primitivas, como a xintoísta e certas psicoses atuais. "Tais aproximações precisas, conclui o autor, entre as concepções primitivas e as psicoses de nossos doentes poderiam esclarecer mutuamente umas e outras, e ficariam assim os psiquiatras reconhecidos aos historiadores das religiões". ${ }^{23}$

Freud e sua escola acabaram por juntar todo esse material fragmentário numa vista sintética, quando tentaram construir uma verdadeira psicologia humana de-

19. Andrew Lang. Mythes, cultes et réligions. Trad. franc. Paris: Alcan, 1896. p. 54.

20. Tanzi. Op. cit., p. 12.

21. Lombroso. L'uomo delinquente. 5. ed. Torino: Bocca, 1896-1897, 4 vols. A sua obra formidável tem sido continuada pos seus discípulos (Ferri, Ferrero, Sergi, Garefalo, Sighele, Rossi etc.) com uma ampla bibliografia e periódicos clínicos dedicados ao assunto.

22. Não quero trazer à baila - hic non est locus - as velhas e emaranhadas discussões sobre a questão do atavismo, tal como o concebeu Lombroso. Lembro, somente, de passagem, a opinião de Ferrero, sobre o delito, considerando-o não um fato de atavismo grosso modo, "in un modo troppo esteriore", como o julgaram Lombroso e Ferri, mas o resultado do atavismo de caracteres psicológicos, tais como a incapacidade para o trabalho e a impulsividade, que "implicam todas as possibilidades criminais mais graves". É a teoria do "atavismo por equivalentes" do delito (G. Ferrero. La morale primitiva e l'atavismo del delitto. Torino, 1896, p. 36). Vide para uma revisão crítica dessas questões: Afrânio Peixoto. Epilepsia e crime. Bahia, 1807.

23. A. M. L'ancienne religion du Japon devant la psiquiatrie moderne. Archivio di Psichiatria, Scienze, penalli ed Antropologia criminale, vol. XXVI. Torino, 1905. p. 629 


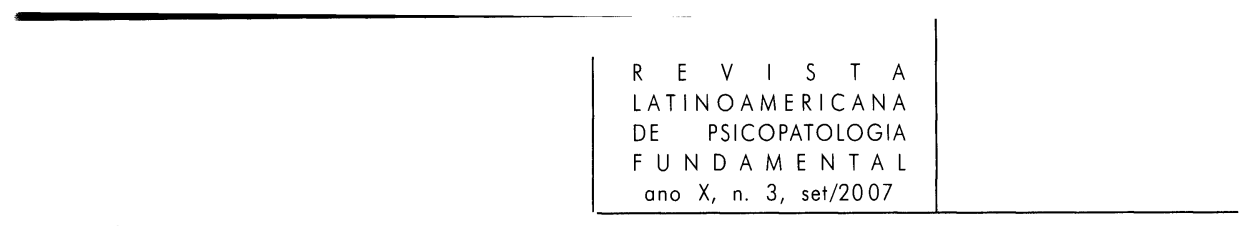

duzida da observação acurada do desenvolvimento mental na criança e na raça. E essa "psicologia das profundidades" (Tiefenpsychologie), como a chamou Bleuler, lançou os seus tentáculos bem longe, na noite imensa do inconsciente da espécie. Entre sonho e arte, e neurose, psicose e pensamento primitivo, só existiriam diferenças superficiais; o mecanismo intrínseco de sua produção seria o mesmo, obedecendo a todos aqueles processos que seus discípulos descreveram: substituições, transportes, condensações, desdobramentos, simbolizações etc., que se encontram descritos minuciosamente nos tratados psicanalíticos.

Foi em sua obra magistral sobre $A$ interpretação dos sonhos (1900), que primeiro Freud descobriu na atividade onírica um processo em tudo semelhante ao do mecanismo mental do homem primitivo. "Na vida noturna, diz Freud, desaparece tudo que dominava em vigília, surgindo como que uma vida ainda jovem e inexperiente, da mesma forma que se encontram no quarto das crianças remotas e primitivas armas, setas e arcos da humanidade adulta". ${ }^{24}$ É o que dizem também todos os comentadores. O sonho é uma espécie de linguagem arcaica que subsiste no "inconsciente" da humanidade; decifra-se como uma escrita ideográfica e utiliza processos de expressão que se encontram nos dialetos primitivos, símbolos humanos, sobretudo sexuais, ambivalência expressiva das concepções com ausência de negações e de contrastes etc." 25

Jung, pela primeira vez em 1907, Bleuler, em 1911, aplicam ao estudo da esquizofrenia os pontos de vista freudianos do sonho; é assim que Jung descobre no pensamento do esquizofrênico "analogias noturnas" (nächste Analogie) com os produtos normais do sonho; Bleuler e a escola desenvolvem, da mesma sorte, noções fecundas que originaram o que se escreveu de mais belo e de mais profundo sobre a psicologia do alienado. ${ }^{26}$

Em sua obra sobre o "Totem e tabu" (1920), Freud mostrou as analogias entre o nevrosado e o primitivo ${ }^{27} \log$ o repetidas e desenvolvidas por sua escola.

E foi justamente fazendo a psicologia da fantasia na criança, no nevrosado, no artista, que os freudistas foram procurar a explicação do seu conteúdo simbólico na imaginação mítica do homem primitivo.

24. "In das Nachtleben, scheint verbannt, was im Wachen herrschte als das psychische Leben noch jung und untuchtig war, etwa wie wir in den Kinderstube die abgelegten primitiven Waffen der erwachsehen Menschheit, Pfeil und Bogen wiederfinden.” (Freud. Traumdeutung, 2 Auflage, 1909, p. 349, citado por Storch, op. cit.)

25. E. Régie e A. Hesnard. La psichanalyse des névroses et des psychoses. Paris:Alcan, 1922. p. 176.

26. Jung. Über die Psychologie der Dementia Praecox, 1907; Bleuler. Dementia Praecox oder die Grüppe der Schizophrenia, 1911, Handbuch der Psychiatrie von Aschaffenburg. (Storch, loc. cit., p. 2).

27. Freud. Totem et tabou. Trad. franc. Paris: Payot, 1925, passim. 


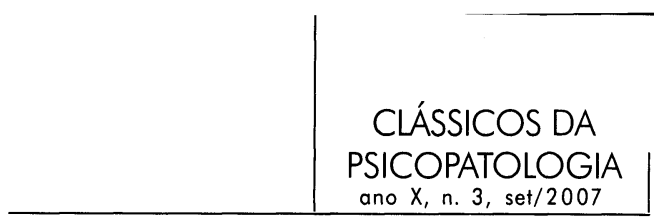

De onde vem, indaga-se Freud, a necessidade destas invenções e onde busca a criança os seus materiais? No que concerne aos móveis, não é possível nenhuma dúvida; mas resta explicar por que as mesmas invenções se reproduzem sempre, e com o mesmo conteúdo. Sei que a resposta que eu mesmo estou a dar a esta questão vos parecerá extremamente ousada. Penso especialmente que estas fantasias primitivas, por que tal é o nome que lhes convém, como aliás a algumas outras, constituem um patrimônio filogênico. Por estas fantasias, o indivíduo submerge na vida primitiva, quando a sua própria vida se tem tornado demasiado rudimentar. ${ }^{28}$

Todos os psicanalistas estão de acordo em admitir a origem filogênica dos símbolos na explicação da simbólica dos alienados; o indivíduo, para eles, como o disse Ferenczi, e analisaremos isso oportunamente, é "um precipitado das experiências das gerações passadas". ${ }^{29}$

A psicologia do artista em suas relações com a nevrose e pensamento primitivo, já ventilada, como vimos, por outros autores, foi objeto de cogitações psicanalíticas, inspirando sobretudo os belos trabalhos de Rank, Stekel etc. "Entre o nevrosado e o poeta, afirmou Stekel, não há nenhuma diferença essencial. Todo nevrosado não é um poeta; mas todo poeta é um nevrosado." ${ }^{30}$ Convém notar que os psicanalistas se separam aqui de Lombroso e sua escola, para quem o artista era um degenerado; para aqueles, a nevrose não é uma degenerescência, é "a flor da civilização". ${ }^{31}$

Para explicar essas analogias, os psicanalistas infelizmente se enveredaram por um dédalo inextricável de vistas apriorísticas, girando em torno do "complexos" sexuais, numa hermenêutica fantasista de audaciosos postulados. Freud e seus discípulos aplicaram assim à psicologia do primitivo as teorias psicanalistas da vida individual, quando seria mais lógico, mais científico, proceder, como o fez a escola dissidente de Zürich, em sentido inverso. A psicologia do simbolismo, tal como a tentou Freud, é um exemplo desse erro.

Se bem que o psiquiatra vienense afirme que a sua simbólica não é mais do que a coordenação dos símbolos legados pelo primitivo, tais como no-lo revelam

28. Freud. Introduction à la psychanalyse. Trad. franc. Paris: Payot, 1925. p. 398 -99.

29. "The deeper psycho-analysis penetrates into the knowledge of social-psychological productions (myths, fairy-tales, folk-lore) the stronger becomes the confirmation of the phylogenetic origins of symbols, which stand out in the mental life of every individual as a precipitade of the experiences of previous generations..." (S. Ferenczi. The ontogenesis of the interest in money. Intern. Zeitschr. f. ärtz. Psychoanalyse, 1914 e Contribution to psychoanalysis. Trad. E. Jones. Boston, 1916. p. 269).

30. Cf. Lalo. La beauté et l'instinct sexual. Paris: Flammarion, 1922. p. 84

31. Lalo. Loc. cit. 


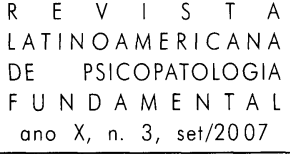

a mitologia, a lingüística, o folclore, ${ }^{32}$ por outro lado aplica à psicologia do primitivo, e é ele mesmo quem o diz, ${ }^{33}$ os dados psicanalíticos da vida individual, com aquele cortejo enorme de uma simbólica erótica à outrance. Essa contradição de Freud não passou absolutamente despercebida dos seus críticos. ${ }^{34}$

Jung emancipou-se desse exclusivismo, admitindo o seu "superinconsciente" (Ueberbewusst)* na explicação de muitos fenômenos da vida psíquica individual. Do seu lado, Bleuler, com as suas pesquisas cheias de uma profunda erudição e originalidade, inaugurou o conceito do autismo, base comum da atividade psíquica do primitivo (mitologia, folclore), criança, arte, sonho psicose, sobre que falarei oportunamente.

A psicanálise, de um lado, concentrando as atenções sobre as semelhanças que existem em condições aparentemente tão diversas como a neurose e a humanidade primitiva; a escola de Burghölzli, do outro, com seus pontos de vista interessantes sobre a psicologia do esquizofrênico, inspiraram os trabalhos recentes de Paulo Schilder e Alfredo Storch, onde esses autores abordam à exaustão o problema da analogia entre loucos e primitivos.

Paulo Schilder se propõe a mostrar a identidade de mecanismo mental entre vários estados patológicos e pensamento imaginativo primitivo. As suas idéias originais sobre a alucinação demonstram que ela não faz mais do que realizar uma transformação mágica do mundo exterior, da mesma maneira como procede o homem primitivo ${ }^{35} \mathrm{Da}$ mesma sorte, o mecanismo da despersonalização, como o da hipocondria, se originariam de um falso conhecimento da realidade, realizariam uma contaminação do mundo externo com o corpo, justamente como sucede no mecanismo mental do selvagem, que não conhece linha de demarcação entre o seu eu e a realidade circunstante. ${ }^{36}$

32. Freud. Introduction à la psychanalyse, p. 185.

33. Freud. Totem et tabou, p. VII.

34. Laumonier, entre outros, critica a interpretação tendenciosa que Freud dá aos símbolos oníricos e psicopáticos, de tinta invariavelmente sexual, frisando a contradição acima referida: "Comment s'y reconnaître et pourquoi accepter l'interprétation de Freud plutôt qu'une autre? Ne seraitil pas dangereux même de préferer celle de Freud, puisque, d'une part, il justifie l'interprétation psychanalytique par le symbolisme traditionnel, et que, de l'autre, il applique la symbolique psychanalytique à l'interprétation des symboles, historiques et légendaires. C'est une pétition de principes." (Laumonier. Le freudisme. Exposé et critique. Paris: Alcan, 1925. p. 150).

* Nota do Editor da seção de Clássicos da Psicopatologia: A tradução contraditória de "superinconsciente" por Ueberbewusst (literalmente, "superconsciente") encontra-se no texto original da dissertação de Arthur Ramos.

35. Paul Schilder. Wahn and Erkenntnis. Eine psychopathologische Studie. Berlim 1818. cap. I, Zur Frage der Halluzination, p. 1 e segs.

36. A psicologia da despersonalização se acha exposta em seu exaustivo trabalho: Selbstbewusstsein une Persönlichkeitsbewusstsein, Berlim 1914, passim. 


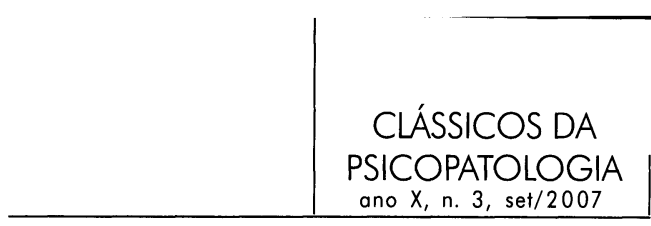

Entre esquizofrenia e primitivo, a analogia seria flagrante e, em seu "Erro e conhecimento", reserva esse autor um capítulo especial em que desenvolve esses pontos de vista. ${ }^{37}$ Para chegar à verificação dessa analogia, partiu Schilder dos estudos dos etnólogos sobre o primitivo, dos trabalhos clássicos de Frazer, Wundt, Ehreareich, mas particularmente das obras de Preuss (Der Ursprung der Religion und Kunst) e de Vierkant (Die Anfange der Religion und Zauberei). Sendo estas questões de que vai tratar muito recentes, assevera que no momento não deseja mais do que frisar o parentesco entre o alienado e o homem selvagem, chamando a atenção dos estudiosos para esses interessantes problemas. Neste particular, "o número dos trabalhos é insignificante, diz ele, não estando ainda completamente elucidadas as questões duvidosas". ${ }^{38}$ As suas observações, o seu material clínico, foram colhidos nos doentes de paranóia crônica (parafrenia) e de esquizofrenia em cujas perturbações mentais vai descobrir analogias evidentes com os processos de feitiçaria e animismo, que Preuss e Vierkant descreveram no homem selvagem. ${ }^{39}$

A obra de Alfredo Storch $^{40}$ é outra contribuição valiosa neste domínio. As suas pesquisas giram em torno da esquizofrenia, e, com Schilder, se inspira nos trabalhos dos etnólogos, aplicando à psicologia do esquizofrênico, entre outros, os dados interessantes de Levy-Brühl sobre a mentalidade primitiva.

É estranhável que estes recentes autores nem de leve citem os trabalhos de Tanzi, que primeiro dentre os alienistas estabeleceu o cotejo entre os documentos etnológicos e demopsicológicos e os psiquiátricos. E se as suas vistas, que se voltam exclusivamente para o capítulo da paranóia, não podem ser hoje aceitas sem restrições, não há de negar que foi o grande alienista italiano quem, muito antes da psicanálise, tentou demonstrar a identidade de processos simbólicos do delírio e da imaginação do selvagem.

Estes são os fatos, ressurgidos agora pelos esforços de uma escola moderna enfeitados com a pirotecnia deslumbrante de teorias novas e encantadoras. Aqui, como em todos os domínios da ciência, mais uma vez se realiza a fórmula de Renan: "as teorias passam; e as verdades necessárias devem ficar".

37. Paul Schilder. Wahn and Erkenntnis. $3^{\circ}$ Cap. Volkerpsychologie und Psychiatrie, p. 57 e segs. 38. "Die Probleme, welche uns im folgenden beschaftigen, sind erst verhältnismässig jungen Datums. Die Zahl der Vorarbeiten ist eine geringe. Die Fragestellungen sind noch nicht vollkommen geklärt. Es kann sich nur um eine mehr vor berreitende Arbeit handeln. Es solien nur prinzspiel wechtige Gesichtpunkte hervorgehoben werden. Detail wird bewusst vernachlässigt”. (Schilder. Op. cit., p. 57).

39. Ibid., p. 60.

40. Alfred Storch. Das archaisch-primitive Erleben, etc. Op. cit. 